\title{
The European Bacillus subtilis genome sequencing project: current status and accessibility of the data from a new World Wide Web site
}

\author{
Ivan Moszer, ${ }^{1}$ Frank Kunst ${ }^{2}$ and Antoine Danchin ${ }^{1}$
}

Author for correspondence: Antoine Danchin. Tel: +331456884 41. Fax: +33145688948. e-mail: adanchin@pasteur.fr

Unité de Régulation de l'Expression Génétique ${ }^{1}$ and Unité de Biochimie Microbienne, ${ }^{2}$ Institut Pasteur, 25-28 rue du Docteur Roux, 75724 Paris Cedex 15, France

Keywords: Bacillus subtilis, genome project, genome sequencing

Sequencing of microbial and eukaryotic genomes has recently gained considerable impetus. In Europe, the concerted efforts of a number of sequencing networks has led to the completion of the yeast genome (Dujon, 1996; Johnston, 1996) and to progress in the sequencing of a plant genome, Arabidopsis thaliana (Goodman et al., 1995), and a microbial genome, Bacillus subtilis (Devine, 1995; Harwood \& Wipat, 1996; Kunst et al., 1995). The genomes of Haemophilus influenzae and Mycoplasma genitalium have been sequenced and published in their entirety (Fleischmann et al., 1995; Fraser et al., 1995), while the genome sequencing of a number of other bacteria of medical, industrial or ecological interest, such as Synechocystis, Mycobacterium, Synechococcus, and several archaeobacteria, is in progress or has been completed (Koonin et al., 1996). The resulting opportunities for whole-genome comparisons will provide valuable insights into bacterial cell physiology and genome evolution (Tatusov et al., 1996).

The progress of the European and Japanese B. subtilis genome sequencing projects up to September 1996 is summarized in Fig. 1. In addition to data from the sequencing project, this figure also includes information from the genetic and physical maps (Biaudet et al., 1996; Itaya, 1993). By agreement with the co-ordinator of the Japanese genome sequencing project, we have defined a new origin for the B. subtilis chromosome that is different from the SfiI site proposed previously (Itaya, 1993). The new origin is located at the point of cleavage within an EcoRV site between the $r p m H$ and $d n a A$ genes (Fig. 2). This newly defined site has the advantage of coinciding with both the origin of replication and the origin of the genetic map, and will provide the basis for future physical mapping of any sequence feature of the $B$. subtilis genome.
The locations of the NotI sites and SfI sites of the previously published physical map have been renumbered according to this new origin (see legend to Fig. 1).

Sequences deposited up to September 1996 in the European B. subtilis DNA sequence database, SubtiList (Moszer et al., 1995), are represented in Fig. 1 as black bars. To facilitate the interpretation of this physical map, the positions of landmark genetic markers have been indicated. Whenever a disagreement exists between the position of a gene on the genetic or the physical maps, the sequence data are used to assign the correct position. The current assignment of regions to participants of the genome sequencing project is also shown. Four additional participants (C. Bruschi, Italy; A. Düsterhöft, Germany; F. Foury, Belgium; M. Vandenbol, Belgium) have recently joined the project and will sequence part of the DNA regions assigned to the European groups.

Since its first release, SubtiList has been updated on a regular basis. In the most recent version (September 1996), SubtiList contains $3311 \mathrm{~kb}$ of non-redundant DNA sequence, $79 \%$ of the $4188 \mathrm{~kb}$ chromosome, extending over 99 contigs. This includes contributions from the European and Japanese sequencing networks (1684 kb and $1195 \mathrm{~kb}$, respectively).

The annotated sequence (June 1996) comprises 2563 protein-encoding genes, 78 tRNA genes, 28 rRNA genes and 3 other RNA genes. A function has been assigned to $992(39 \%)$ of the protein-encoding genes - with or without experimental evidence - while 1571 genes (61\%) encode products of unknown function and are consequently identified by the starting letter ' $y$ '. Known gene products can be ascribed to 45 functional categories (Table 1), an original classification derived from a number 

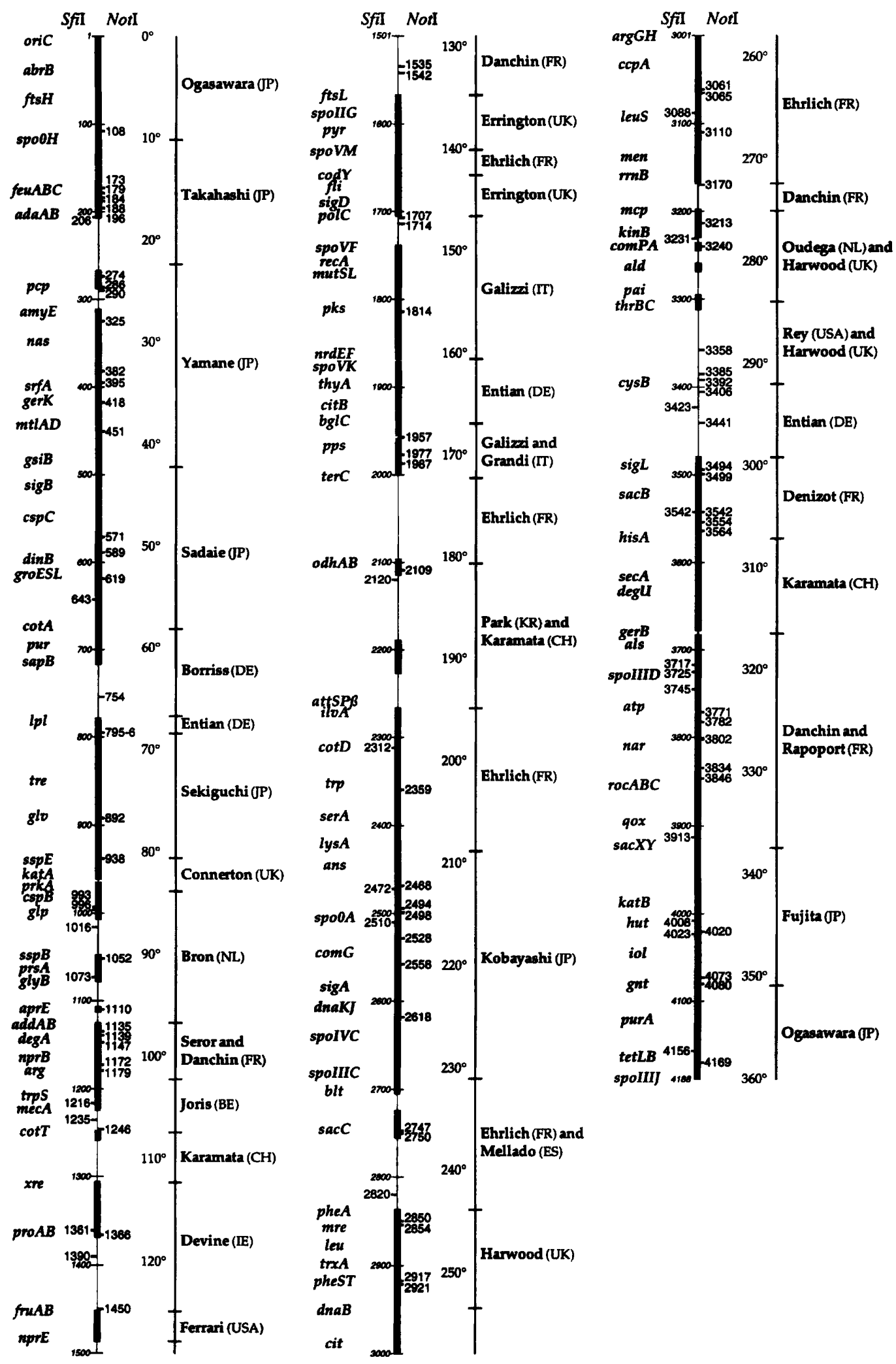

Fig. 1. Physical, genetic and sequence map of the $B$. subtilis genome. According to the new origin of the chromosome (see text), Notl and Sfil sites have been assigned new positions as compared to the original physical map: $32 \mathrm{~kb}$ has been subtracted for sites located before the $18 \mathrm{~N}$ Notl fragment (position 451-571), and $9 \mathrm{~kb}$ ( $32 \mathrm{~kb}$ minus $23 \mathrm{~kb}$ ) for sites located after the $18 \mathrm{~N} \mathrm{Notl}$ fragment, taking into account the $23 \mathrm{~kb}$ deletion found in the strain originally used for construction of the physical map. BE, Belgium; CH, Switzerland; DE, Germany; ES, Spain; FR, France; IE, Ireland; IT, Italy; JP, Japan; KR, Korea; NL, The Netherlands. 
Table 1. Functional classification of the known gene products of $B$. subtilis

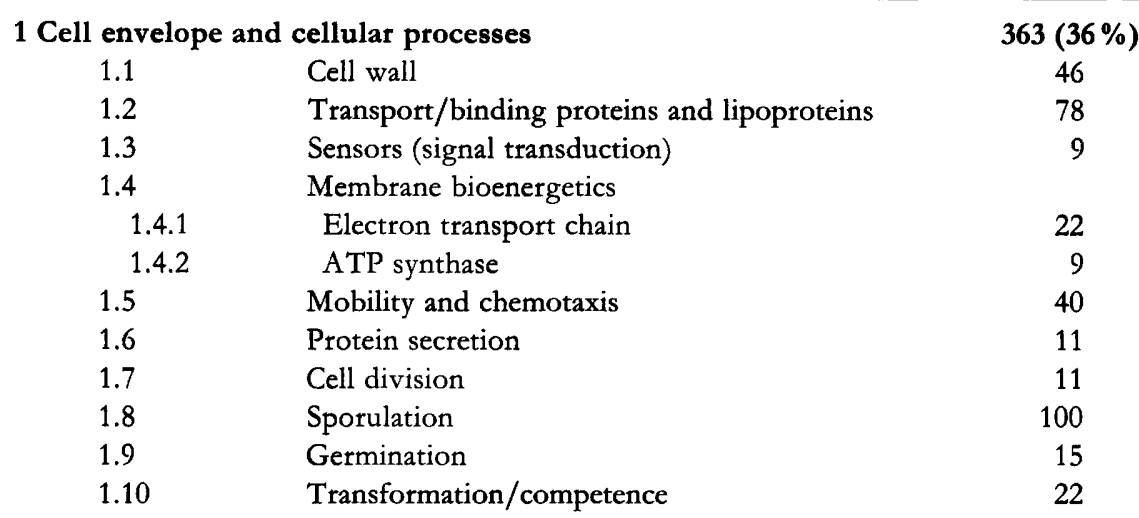

$\begin{array}{ll}2 \text { Intermediary metabolism } & 299(30 \%)\end{array}$

2.1 Metabolism of carbohydrates, sugar alcohols and amino sugars

$\begin{array}{lll}2.1 .1 & \text { Specific pathways } & 48\end{array}$

$\begin{array}{ll}2.1 .2 & \text { Main glycolytic pathways } \\ 2.12\end{array}$

2.1.3 Pyruvate dehydrogenase complex 4

2.1.4 TCA cycle 11

2.1.5 Fermentation 11

$2.2 \quad$ Metabolism of amino acids and related molecules $\quad 96$

$2.3 \quad$ Metabolism of nucleotides and nucleic acids 53

$2.4 \quad$ Metabolism of lipids 11

2.5 Metabolism of coenzymes and prosthetic groups $\quad 52$

2.6 Metabolism of phosphate 1

2.7 Metabolism of sulfur 0

$\begin{array}{ll}3 \text { Information pathways } & 208(21 \%)\end{array}$

3.1 DNA replication 12

3.2 DNA restriction/modification and repair 11

$\begin{array}{lll}3.3 & \text { DNA recombination } & 7\end{array}$

3.4 DNA packaging and segregation 6

$3.5 \quad$ RNA synthesis

3.5.1 Initiation 11

$\begin{array}{lll}3.5 .2 & \text { Regulation } & 70\end{array}$

3.5.3 Elongation 6

3.5.4 Termination 3

$\begin{array}{lll}3.6 & \text { RNA modification } & 2\end{array}$

3.7 Protein synthesis

$\begin{array}{lll}3.7 .1 & \text { Ribosomal proteins } & 47\end{array}$

3.7.2 Aminoacyl-tRNA synthetases 18

$\begin{array}{lll}3.7 .3 & \text { Initiation } & 4\end{array}$

$\begin{array}{lll}3.7 .4 & \text { Elongation } & 2\end{array}$

$\begin{array}{lll}3.7 .5 & \text { Termination } & 1\end{array}$

3.8 Protein modification 3

3.9 Protein folding 5

4 Other functions

4.1

4.2

4.3

4.4

4.5

4.6

$66(7 \%)$

Adaptation to atypical conditions

11

Detoxification

3

Antibiotic production

Drug/analogue sensitivity

17

Transposon and IS

29

5 Miscellaneous

$56(6 \%)$ 


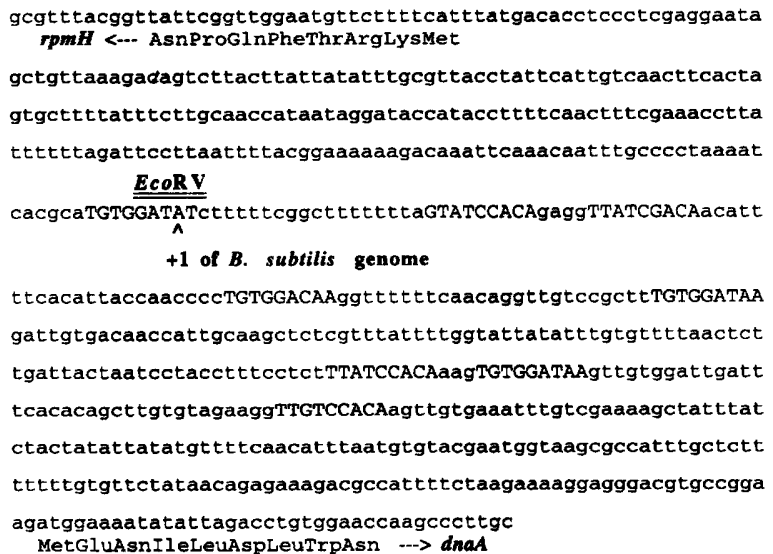

Fig. 2. New origin of the $B$. subtilis chromosome. DnaA boxes are indicated with upper case letters.

of others previously defined (Riley, 1993; Selkov et al., 1996; N. Ogasawara, personal communication).

The gene products of unknown function have been divided into three classes: (i) those which show similarities with proteins whose function is known; (ii) those which show similarities with other proteins of unknown function; and (iii) those which do not exhibit any significant similarity with proteins in public data banks. Among the 1571 gene products of unknown function, $545(35 \%)$ fall into class (i), either because they show similarities with proteins whose function has been precisely demonstrated, or because they clearly belong to large functional families of proteins (such as sensor kinases and response regulators of two-component signal-transduction systems, LysR transcriptional regulators, $\mathrm{ABC}$ transporters, etc.), thus providing useful assistance in the elucidation of their actual function. Among the remaining gene products of unknown function, $290(18 \%)$ belong to class (ii) and 736 $(47 \%)$ to class (iii). Together, these 1026 gene products whose role cannot be predicted represent $40 \%$ of those currently available for $B$. subtilis. This is in line with observations made during the course of other genome sequencing projects (Dujon, 1996; Fleischmann et al., 1995), emphasizing the large proportion of genes that classical approaches have neglected. A systematic gene functional analysis programme supported by the European Commission has been initiated to challenge this issue (contract BIO2-CT95-0278).

The SubtiList database is available as a Macintosh or Windows stand-alone application - 4th Dimension (4D) runtime - by anonymous ftp at the URL $\mathrm{ftp}: / /$ ftp.pasteur.fr, directory pub/GenomeDB/ SubtiList. A World Wide Web (WWW) server has been set up recently (S. Brouillet and others, unpublished), taking advantage of the implementation of SubtiList on a UNIX system using the Sybase relational database management system. This server makes use of the same type of interface as the 4D version of SubtiList. The user can therefore navigate between the various sections of the database (contigs, genes, proteins), establish logical links between different types of information, and perform multicriteria searches. Moreover, hyper-text links facilitate the retrieval of relevant information on B. subtilis gene and protein sequences from the EMBL (EBI server), SwissProt and ENZYME data banks (ExPASy server). A number of sequence analysis tools, such as rapid protein sequence comparisons (BLAST, FASTA) and DNA or protein pattern searches, are also directly accessible for the analysis of $B$. subtilis sequence data. The SubtiList WWW server can be reached at the URL http://www.pasteur.fr/Bio/SubtiList.html

\section{Acknowledgements}

This work was supported by the European Commission under the Biotechnology programme (contract numbers BIO2-CT93-0272 and BIO2-CT94-2011). Biotechnology companies, including Dupont de Nemours (USA, France), Genencor International (Finland, USA, The Netherlands), F. Hoffmann-La Roche (Switzerland), Novo Nordisk (Denmark, USA), Puratos (Belgium), Roussel-Uclaf (France), SmithKline Beecham Pharmaceuticals (UK) and Gist Brocades (The Netherlands), provided additional funds within the framework of the Bacillus industrial platform. The work from our laboratories was supported by funds from the Institut Pasteur, the Centre National de la Recherche Scientifique, and the Ministère de l'Éducation Nationale, de l'Enseignement Supérieur et de la Recherche. We are grateful to the Association Française contre les Myopathies for the loan of a computer workstation. We also thank S. Brouillet and L. Jones for their help in elaborating the WWW server. We would also like to thank C. Harwood and K. Devine for critical reading of this manuscript.

\section{References}

Biaudet, V., Samson, F., Anagnostopoulos, C., Ehrlich, S. D. \& Bessières, P. (1996). Computerized genetic map of Bacillus subtilis. Microbiology 142, 2669-2729.

Devine, K. M. (1995). The Bacillus subtilis genome project: aims and progress. Trends Biotechnol 13, 210-216.

Dujon, B. (1996). The yeast genome project: what did we learn? Trends Genet 12, 263-270.

Fleischmann, R. D. and others (1995). Whole-genome random sequencing and assembly of Haemophilus influenzae $\mathrm{Rd}$. Science 269, 496-512.

Fraser, C. M. and others (1995). The minimal gene complement of Mycoplasma genitalium. Science 270, 397-403.

Goodman, H. M., Ecker, J. R. \& Dean, C. (1995). The genome of Arabidopsis thaliana. Proc Natl Acad Sci USA 92, 10831-10835.

Harwood, C. R. \& Wipat, A. (1996). Sequencing and functional analysis of the genome of Bacillus subtilis strain 168. FEBS Lett 389, 84-87.

Itaya, M. (1993). Physical map of the Bacillus subtilis chromosome. In Bacillus subtilis and Other Gram-positive Bacteria: Biochemistry, Pbysiology, and Molecular Genetics, pp. 463-472. Edited by A. L. Sonenshein, J. A. Hoch \& R. Losick. Washington DC: American Society for Microbiology.

Johnston, M. (1996). Genome sequencing: the complete code for a eukaryotic cell. Curr Biol 6, 500-503. 
Koonin, E. V., Mushegian, A. R. \& Rudd, K. E. (1996). Sequencing and analysis of bacterial genomes. Curr Biol 6, 404-416.

Kunst, F., Vassarotti, A. \& Danchin, A. (1995). Organization of the European Bacillus subtilis genome sequencing project. Microbiology 141, 249-255.

Moszer, I., Glaser, P. \& Danchin, A. (1995). SubtiList: a relational database for the Bacillus subtilis genome. Microbiology 141, 261-268.

Riley, M. (1993). Functions of the gene products of Escherichia coli. Microbiol Rev 57, 862-952.

Selkov, E., Basmanova, S., Gaasterland, T., Goryanin, I., Gretchkin, Y., Maltsev, N., Nenashev, V., Overbeek, R., Panyushkina, E.,
Pronevitch, L., Selkov, E. \& Yunis, I. (1996). The metabolic pathway collection from EMP: the enzymes and metabolic pathways database. Nucleic Acids Res 24, 26-28.

Tatusov, R. L., Mushegian, A. R., Bork, P., Brown, N., Hayes, W. S., Borodovsky, M., Rudd, K. E. \& Koonin, E. V. (1996). Metabolism and evolution of Haemophilus influenzae deduced from a whole-genome comparison with Escherichia coli. Curr Biol 6, 279-291.

Received 26 June 1996; accepted 13 August 1996. 